DOI: 10.2478 /ausfm-2014-0025

\title{
The Sensation of Time in Ingmar Bergman's Poetics of Bodies and Minds
}

\author{
Fabio Pezzetti Tonion \\ Museo Nazionale del Cinema (Torino) \\ E-mail: fabio.pezzetti@libero.it
}

\begin{abstract}
Bergman's cinema does more than just focus on a personal reflection of the body as an emotive and emotional vector; his cinema, through the transitory fragility of the human body as represented by his actors, defines the possibilities of a perceptive horizon in which the experience of passing time becomes tangible. Even though the Swedish director's entire opus is traversed by this reflection, it is particularly evident in the films he made during the 1960s, in which the "room-sized" dimension of the sets permits a higher concentration of space and time. In this "concentration," in this claustrophobic dimension in which Bergman forces his characters to exist, there is an often inflammable accumulation of affections and emotions searching for release through human contact which is often frustrated, denied, and/or impossible. This situation creates characters who act according to solipsistic directives, in whom physiological and mental traits are fused together, and the notion of phenomenological reality is cancelled out and supplanted by aspects of dreamlike hallucinations, phantasmagorical creations, and psychic drifting. Starting from Hour of the Wolf, this essay highlights the process through which, by fixing in images the physicality of his characters' sensations, Bergman defines a complex temporal horizon, in which the phenomenological dimension of the linear passage of time merges with, and often turns into, a subjective perception of passing time, creating a synchretic relationship between the quantitative time of the action and the qualitative time of the sensation.
\end{abstract}

Keywords: Ingmar Bergman, perception of space and time, sensations.

Starting in the mid-1950s, the close correlation between Bergman's cinema and the possibility of representing time in film became evident. French film critique played a key role in this respect, highlighting a central aspect of a film opus in continuous evolution that went through various phases concluding with diverse outcomes (Rohmer 1956, Béranger 1957, Godard 1958, Hoveyda 1959).

Eric Rohmer noted how Bergman recognized cinema's ability to represent life and its unadulterated length, divesting it of intrigue and suspense, and showing 
that life is, basically, monotonous (Rohmer 1956, 7). This became the defining trait of a type of cinema that represents a potential capitulation to a flow of time which captures every qualitative level and not just those which create strong dramaturgical and narrative dimensions (Steene 2005, 131-141).

In his critique of Prison (Fängelse, 1949), Jean Douchet analyzed the film from an ethical standpoint which considered Bergman's desire to explain the presence of hell which reigns on earth as the fulcrum of the filmmaker's poetics, and introduced the concept of "instant privilégié." To the French critic, this is a moment of equilibrium between the protagonists' realization of the cruelty and indifference of the world and the possibility of experiencing a moment of joy and peace - despite everything. Actually, more than an equilibrium, it is a suspension in the flow of the pain of time, which, as it crystallizes itself in an instantaneous dimension, removes those experiencing it from the chronological flow of time and places them in a privileged and abstract dimension which, nonetheless, is destined to disappear almost instantaneously (Douchet 1959, 52).

Douchet's reasoning is interesting and productive when it evokes the gaze, that act of looking which is so closely tied to how the gazer's face is filmed, and regards Godard's reflection that Bergman is the filmmaker of the instant (Godard 1958, 2). The Swedish director demonstrated not only the desire to use the cinematographic means in virtue of its fundamental ability to mold time, but also and above all, of the possibility it offers to subject time to a continuous metamorphosis which captures it qualitatively and develops it quantitatively by acquiring, mastering, and giving new meaning to conventional and proven narrative structures (for example, the flashback) and to a spatial dimension involving the mise-en-scène and the shots, above all of the face. This paper is based on the conviction that, even though Bergman's films are populated with figures who embody Time (in particular, the representation of Death, a pervasive presence in the Swedish director's filmography), the focal point of a reflection on the possibility of analyzing temporality in film lies in how the body and, more specifically, the face are represented.

Jacques Aumont suggests that Ingmar Bergman's mature filmmaking phase coincided with his invention of forms showing the process of possession and abstraction of the face, which no longer refers to a purely physical dimension but also embodies a subsequent level of the person's alteration. To Aumont, Bergman perfected these staging techniques of close-ups and full close-ups in his tetralogy of films shot on the island of Fårö - characterized by his study "of neurosis in its relation to the mental image,"- establishing a parallel between practices of 
stylization and abstraction aimed at defining a limit of the subjective and memorybased dimension (represented by qualitative time), and its relationship with a spatial dimension as characteristic as that of the close-up (Aumont 2003, 170).

Bergman's creation consisted in perfecting what Aumont defined as the "hyper-close-up," in which the identifying form of a person (the face) is spatially constrained within the edges of the frame, thus liberating its clarity and expressivity (Aumont 2003, 170) [Fig. 1]. The Swedish filmmaker's opus progressively distanced itself from psychologizing ways of representing the human face and created a new way of staging the spatiality of the actor's body that also influenced the temporal dimension. Two frames are emblematic of the evolution in Bergman's use of the close-up in his reflections on time: the first features Maj-Britt Nilson (in the role of Mårta) and is taken from Waiting Women (Kvinnor väntan, 1952); the second is from Cries and Whispers (Viskningar och rop, 1972) and shows Liv Ullmann (in the role of Maria) visiting her bedridden sister in Agnes's "resurrection" scene [Figs. 2-3]. The narrative, psychological dimension prevails in Waiting Women; on the other hand, Cries and Whispers is based on the juxtaposition and clash between the deconstruction of the story and the characters, and the intensification of classical dramaturgy using pre-modern cinematographic technology (Neyrat 2007, 12). Although Waiting Women is constructed on three flashbacks, its temporality is linear. In Cries and Whispers, the temporal dimension is shattered and challenged, and there is no clear confine between the "real" world and the one created by the altered reality of dreams and memory; the close-ups of the protagonists lie at the junction of this problematic temporality, in a fluctuating structure generated by the interiority of the characters and by delving into the singularity of psychic time.

During the 1950s, Bergman believed that the close-up still had the value of emphasizing feelings: it traced them, underlining and rendering them explicit. Later, the close-up became an instrument for stylizing space and concentrating time. This can occur by shattering the temporal dimension, pushing it to the limit; in this dimension, a clear division is drawn between the "real" world and the one created by the altered reality of dreams, memory, the peculiarity of psychological time (Gervais 1999, 122).

It also occurs in the close-up of Märta reading the letter in Winter Light (Nattvardsgästerna, 1963), a close-up which blends together not just different temporalities but different experiential situations, as well (that of Märta and that of Tomas Ericsson). Thus, faced with what can technically be considered two equivalent planes, Bergman introduced a sideslip which tempers the passage 
from one form of mise-en-scène to another and renders time visible through close-ups of the face (cf. Aumont 1992, 100) [Fig. 4].

The method used by Bergman to make time perceptible is to insist on the body, denuding it through a process of painful unveiling which is often accompanied by monologs, with the character gazing at the mirror image of his own conscience or that of others. A mirror which is not only metaphorical, since it becomes the tangible and privileged object in which the characters reflect themselves and reflect on themselves. The mirror is the instrument which separates face from body, isolating it. It enables one to choose the unique, identitary cipher of the body, isolating it and insisting on it: in Bergman's films, the face becomes a sensorial space on which the director's camera registers the passing of the instants. But, in his films, images of the face are not always accompanied by the use of a mirror: this might be the instrument which thematizes the use of the face, but its function is, in fact, to focus the gaze on what is being reflected. An equivalency can be established between the techniques used to stage the reflected image of the characters (which "doubles" the subjects, making them unstable, forcing them to confront themselves) and that of the full-face close-up shot of the characters. Thus, just like a mirror offers its own evidence to the person looking into it, the full-face shot offers the spectator the naked evidence of the character, providing a mirror-effect which tends to reflect a vision of pure time, objectively correlated to a distressing idea of mortality, of impending death.

Winter Light is perhaps the most evident example of this practice. In this film, Bergman proposes interesting stylistic features in his portrayal of temporality: the long scene in which the letter is re-cited by Märta Lundberg is, in the bodytime of the film, a moment of otherness which, rather than interrupting the chronologically linear dimension of the film and its unity of time-place-action, indicates instead a possible and concrete elsewhere. That is, Bergman creates a double level of temporality, a fringe of the past that becomes crystallized in the present and places it under constant tension. Through this tension, he makes time manifest: it is as though he can visualize time and make it perceptible in the concrete experience of its flow. Regarding the relationship of cinema with time and becoming, Paolo Bertetto writes that "the filmic image is [...] a moving image which shows the flows of things in space and time, produced by the miseen-scène;" these images are able to also show "in a clear manner the temporal character of people and things. Everything that is visible appears in a temporal articulation and the things are distributed along the temporality of the flow. The moving image, therefore, very clearly articulates the procedural fluidity and the 
spatial transfer of things, as well as the temporal character of the flow, of its state of being chronos" (Bertetto 2010, 159-160).

An austere and stringent film, Winter Light marks a radical break in Ingmar Bergman's cinematographic style: striving for intense stylistic perfection that revolves round the aesthetic pole of realism (Donner 1970, 119), forced into the three unities of time, place, and action, the film nonetheless tends toward a dimension of the abstraction of phenomenological reality which finds particular relevance in the filmmaker's pondered use of the close-up and its associated temporality. In fact, even when the mise-en-scène disallows the close-up, it is evoked by its very absence, as in the long scene in which the body of Jonas Persson, who committed suicide, is found. Filmed as a long shot - bearing detached and objective witness, - the scene depicts the impossibility of communication between individuals [Fig. 5].

By disallowing a close-up of the face, the emotional vector par excellence, it manifests the moral and human defeat of the pastor Tomas Ericsson and creates an ultimately excruciating sensation of passing time. The film is constructed in the present; what matters is the ongoing, unrepeatable moment in which existential solitude is experienced (portrayed by a simple mise-en-scène, in which the actor's body is the inevitable focal point of a plane which tends to annul itself in the void): to the characters in this film, time is pain; in fact, if the objective use of space contributes to creating a feeling of isolation, the subjective perception of time highlights the crisis of the present, which is full of suffering and doubt.

Bergman, through his work on space and the actor's body, achieved a more aware and mature confrontation with the possibilities of representing time. Time becomes flesh, it assumes a physical, emotional, and spiritual concreteness in bodies whose actions and decay are brazenly flaunted by the director [Fig. 6]. The many ill characters (in whom the illness undermining the physique is also the metaphor of an infirmity of the soul and refers to a spiritual dimension that is able to transcend the confessional and religious limits which have often been used to interpret Bergman's cinema) populating his films embody a private pain which is often viewed as universal. This pain, in its visual effects on the body, marks the inexorable passage of time which consumes and destroys, and which often does not even leave the illusory comfort of memory, because even memories are often bent to a logic of lies which reflects the inevitable moral, relational, and human defeat of the characters. The pastor Tomas Ericsson is emblematic of this approach; he constructs a fictitious memory that is a far cry from the reality of his personal relationship with his defunct wife. The inability to accept the painful 
evidence of the failure of human and emotional relationships is the theme of Cries and Whispers, a film which is entirely constructed on the resurfacing of memories which are irreconcilable with the defensive reality which the protagonists have tried to erect around themselves.

Märta Lundberg's blistered hands in Winter Light, Ester's body wracked by consumption in The Silence (Tystnaden, 1963), and Agnes's cancer-riddled body in Cries and Whispers are only a few of the most obvious examples of an opus that is able to render the physicality of pain concrete and perceptible, of the miseen-scène of bodies consumed by time and consecrated to consuming themselves in death. This ability of Bergman is even more exceptional if one takes into account that these three films belong to the period in his career during which he consciously espoused techniques of explicit stylization. If the mise-en-scène tends toward sobriety in the adopted solutions, these solutions insist on the actors (the true measure of Bergman's cinema), exalting their possibilities and capturing (and transfiguring) their physical concreteness. Thanks to his experience in the theater (where what counts is the here and now of the unrepeatable presence of a body determined by time and performing within a space), Bergman transferred to his films an awareness of their ability to also represent the flow of time, encapsulated in a body that is inevitably destined to be annulled: hence, the exceptional value attributed to the instant. Michel Estève stresses the fact that "in opposition to Sartre's thesis, according to which the present is nothing other than an escape, a flight from death and empty perdurance, Christian existential conception (to which both Bernanos and Kierkegarrd adhered) underlines the exceptional value of the instant, an intersection point between eternity and our temporality, the possible fullness of time and duration" (Estève 1966, 67).

But time which consumes the body is also time which corrodes human relationships: to stage and film the process with a camera that follows it throughout its duration means to tread a path that unveils the lie and leads to a dimension of annulment. And to work on the image in order to push it toward the limits of the void was one of the objectives Bergman pursued in some of the key films of his opus. Reflecting on the cinematographic images of Bergman's films of the 1960s, Jean Narboni writes that "long confined to the margins of his films, the silent forces and their power to create the voids surreptitiously slipped into their very texture, softening the outlines and blurring the boundaries" (Narboni 1967, 41).

Persona is the film which most explicitly confronts this limit, reflecting on the role of cinema as a device and the dimension inherent to the individual person. Enclosed between a prologue and an epilogue which thematize the meta- 
cinematographic dimension, constructed almost entirely of close-ups and long takes, Persona is representative of the tension of research in Bergman's films from the 1960s, research which invests the meaning and the use of the closeup. An emblematic synthesis of a process of subtraction and abstraction (which veers toward destruction: of the screen, of the device, of the character, and of the narration), the film problematizes the correlation between the close-up of the face and the psychological dimension of the subject. In depicting Elisabet Vogler, Bergman highlights the parallelism between the physical dimension and what could, for simplicity's sake, be defined as the spiritual dimension of a person who is drawn toward his or her own depletion and annihilation. Aumont writes: "To represent a face, to draw a portrait (whether or not it belongs to the pictorial genre known as 'portraiture'), means to contemporaneously search for two things: resemblance and, again, resemblance. Visual resemblance, which can be empirically detected by the eye, which can be adjusted through artifices of the atelier, which can be analyzed in localized similitudes, in proportions; and the spiritual - or simply personal - resemblance, which cannot be detected but which can be sensed, which cannot be analyzed but which carries conviction" (Aumont 1992, 26-27).

This dimension of abstraction also regards the characters, whose faces undergo a process of metamorphosis which confounds their identifying contours, both from a physical point of view and from the point of view of their relationship with the surrounding world. To this regard, Steve Vineberg writes: "The mystery at the heart of Persona is the mystery of identity, articulated by Bergman and his two actresses chiefly in two ways. The first is the mirror exercise, in which we cannot say for sure which of the two women is the initiator and which is the responding mirror. The other is the metamorphosis, a process whereby an actor undergoes a dramatic mutation of some kind. [...] The central image of Persona - the unforgettable 'mirror' shot in which the two women's faces merge - is, of course, an image of metamorphosis” (Vinenberg 2000, 124).

Persona intentionally creates a world that is suspended between the concreteness of reality and the impalpability of dreams, a complex sur-reality which ends up acquiring the traits of the subjective world of the protagonists, setting in motion a process of osmosis, by means of which the mental subjectivity of the characters tends to invade and dominate the objectivity of the physical world [Fig. 7]. Persona is a psychological battleground, on which the individual subjectivities of the protagonists fight for the expressive territory which exalts the individual and becomes the location expressing the soul: the close-up, the 
location of the con-fusion between the objective dimension afferent to the world and the character's own subjectivity [Fig. 8].

In the foundational figure of the close-up and full close-up, Bergman experiments with the possibilities of a new type of cinema, freed of the urgency to confront reality and assuming aspects which are increasingly frayed, undefined, ephemeral. In a cinema on the threshold of life which always overlaps with Death (evoked, suggested, and ambiguously represented), an obsessive and constant figure casting its long shadow even in films consecrated to summertime and love, is embodied in a "last, powerful, and abstract image: time" (Aumont 2003, 126). Bergman confronted time by using two apparently different methods that are actually complementary and interconnected: thematizing and reflecting on the best cinematographic means for rendering time perceptible. Over the years, by working on the possibilities of and the many methods for staging an instantaneous temporality (able to capture life as it unfolds but also to concentrate on the precise instant in which it seems to suspend itself and hover in a dimension that is not within the jurisdiction of the chronological passage of time), Bergman constantly redefined the canons of his own film technique, passing from the extreme freedom and ease of the filmic with regard to the profilmic, to his desire to closely control the shots. By thus passing from the forms of a free cinema to those of a rigorous cinema, the director constantly expanded his own reflection on time and the possibilities of its representation, starting with methods of chronological analysis and ending with extreme forms of abstraction.

Like Winter Light, the film Hour of the Wolf (Vargtimmen, 1968), too, explores the duration of time but it also opens up to another reflection and a new level of ambiguity: reality (or rather: "here is time") which falls into a hallucinated dimension (or rather: “which time?"). Similar to The Face (Ansiktet, 1958) in both its thematic choices (the humiliation of the artist, the fusion of reality and the fantastic) and its stylistic ciphers (the continuous friction between objective and subjective elements, between various levels of reality and the possibility of experiencing the sur-reality of magic and dreams), Hour of the Wolf is the film which carries the hallucinatory dimension of Bergman's opus to the extreme. Like a true Strindbergian "ghost sonata," the film is populated by vampire-like characters moving within a mise-en-scène in which the confines of nightmares entwine with those of awakening.

The film also addresses methods of mise-en-scène and questions of temporality with which the director had already experimented in Wild Strawberries (Smultronstället, 1957). In fact, in Wild Strawberries, Bergman explicitly deals 
with the theme of time. If his previous films had clearly displayed complex and sophisticated research on the portrayal of temporality, this film compares quantitative time and qualitative time, and clearly reveals the theoretic deviation which the filmmaker would imprint on his opus from then on. Wild Strawberries is the laboratory in which he experiments in depth with possible ways to render the constant fluctuation between the quantitative and the qualitative dimensions in how time is experienced. For example, observe how his flashbacks have more than just an evident dramaturgical function; they are also endowed with an added significance because his structuring of the film creates a virtual confusion in its temporal levels. In other words, Bergman gives the flashback a double role: it ferries the story from one temporal dimension to another, dimensions which are nonetheless characterized by a quantitative acceptance (time which has passed, which can be measured), and, at the same time, it creates a fracture in the chronological dimension, into which he inserts the qualitative experience of time. Moreover, in Wild Strawberries, Bergman begins to consciously display his own desire to create a type of cinema which studies the possibility of comprehending the many levels of reality: in fact, the filmmaker held that if cinema can pay attention to a strictly phenomenological dimension of reality (through a mechanism that exploits the illusion), it can also create a sur-real dimension. In other words, a dimension that contains phenomenological reality, but which is difficult to perceive. This highlighting of the sur-real derives from cinema's ability to deal with a plurality of times, above all with qualitative times which define the experiential horizon of the characters.

Let us now consider the construction of Hour of the Wolf, in order to try to understand how Bergman's work on temporality led to the re-definition of a particular type of film image which is characterized by its relationship to the ambiguous dimension of fantastic temporality. This re-definition is a type of confirmation, an institutionalization of a constitutive process of which traces can be found in past experiments since, as Jacques Aumont notes, already with Persona Bergman invents "a new statute of the filmic image. No longer an indication, a trace which is ontologically coupled to the appearance of reality. No longer fantasies or pure extravaganza. But rather the enchanted realism of interior images" (Aumont 2003, 161-162). Hour of the Wolf, which is born in a dimension of problematic and hallucinated realism, which develops in the ambiguous confrontation of the realities of the two protagonists (Johan and his wife Alma), which clashes and concludes with a horrific dimension that has almost an expressionist matrix, takes the intuitions of Persona and pushes them 
toward the outer limit of obscurity. The light treatment in this film is carefully calibrated: the characters are engulfed and swallowed up by darkness, and light is constantly battling obscurity. Moreover, when light is present, the images are over-exposed to the point that everything is precipitated into a hallucinatory atmosphere of nightmares that are coming true.

The film opens with a monolog by Alma, who is looking straight into the camera [Fig. 9]. This mise-en-scène is important not just because it is repeated in the finale of the film, in which the woman is talking to an invisible listener, but also because it is preceded by the sounds of the scene itself being prepared. We can hear the prop men moving objects and movie cameras around on the set, we can presumably hear Bergman coaching Ullmann on how to interpret the scene. Thus, we are faced with a procedure of alienation which, on the one hand, makes it more difficult for us as the spectators of the cinematographic device Bergman is setting up, and, on the other, represents a different time with respect to the story which the film is about to present us. We are faced with an initial fracture of the film's temporal reality, or better, of the temporal continuity of the story's main level. We realize that the time of the filming is about to be substituted by the time of the film: and a very special film it is, with its fantastic and dreamlike dimension.

Within the framework of Alma's monologs which open and conclude the film (which support this framework and give it meaning, making us perceive the film as a story told by the woman), the story unrolls as a complete flashback. At first glance, Hour of the Wolf is the narration of Johan Borg's crisis, which he recounts to his wife after he has already died. We are confronted with yet another temporal level, a critical moment of the past: the past as a dimension of memory in which the recollections that are sparked bear the seed of ambiguity, of fallaciousness, of the possibility of not existing. From this point of view, the shot of Alma Borg as she observes the painting of Veronica Vogler on the wall in Baroness von Merkens's bedroom is emblematic. We know that the woman is looking at the painting but we don't see it and never will. The painting, the portrait which brings the past concretely into the present, is annulled, as is the period of time which could have been conserved in it: the only time which remains is the duration of the shot, which is filled with Alma's interior time [Fig. 10].

A further loop of this spiral evolution of time is proposed right after the apparition of the Old Lady (Naima Wifstrand), who tells Alma where she can find her husband's diary. This episode is of dual importance to the economy of the film: it is the first moment in which the dimension of ambiguity (which is a prelude to the fantastic) is linked to time. In what sense? In the sense that the 
statute, the index of reality of the Old Lady, is never made clear. She might be a real presence but then again she might be a ghost. Or rather, it is possible that Alma, too, in virtue of her love and cohabitation with Johan, sees the same ghosts her husband sees (and, in fact, the film closes with this question).

Bergman insists on this element of ambiguity; rather than limiting himself to dialog (with the Old Lady's slip of the tongue, when she first says she is 216 years old and then corrects herself, saying she is 76), he uses a precise strategy in the mise-en-scène. First we see Alma taking a blanket outside and spreading it out on a table to air; then, when she senses that someone is standing behind her, she turns around and the movie camera pans until it comes to a stop on the Old Lady. From that moment on, we are authorized to believe in the actual presence of the Old Lady, except for the fact that the director never shows Alma and her together in the same frame. And when the old woman goes away, the doubt remains: Alma is shown on her own and the long shot seems to confirm that until that moment she really has always been by herself. The doubt that this sequence generates grafts a dimension of altered reality onto the fabric of the film; in this sequence, we are confronted with a moment of suspended and uncertain temporality, in which chronological, objective time is substituted by a dimension of time which is purely personal: the dimension of the character's interiority. However, it must be immediately stressed that, in the case in question, this is true only after the whole film has been viewed, because at that particular moment the narrative has not yet been developed enough for us to propend for either the real or the fantastic dimension. At this point in the film, we can only have doubts, no certainties - above all regarding Alma. It is interesting to note that, before this sequence, Bergman had proposed a reflection on the concreteness of the duration of time. Johan looks at his watch and tells his wife not to fall asleep before dawn has broken, after which he times one minute, as though to define a very precise horizon of objective temporality, which is tied to the seconds as they pass. From this point of view, time which never passes, which becomes an oppressive and unbearable weight, could be the key to our approach to the film [Fig. 11].

As mentioned above, the apparition of the Old Lady who reveals the existence of the diary leads to another twist, which undermines the temporal dimension which had been created such a short time before. In fact, as Alma reads her husband's diary, she activates three suspensions of the linear passage of time: her reading evokes three encounters Johan Borg had on the island, the first with Baron von Merkens, the second with his former lover Veronica Vogler, the third with Mr. Heerbrand. The nature of these suspensions (or flashbacks within the 
principal flashback, which is the film itself), of these disturbing fractures which disrupt our comprehension of temporality, is ambiguous and it shifts the film from the dominion of reality to that of unreality, of mental creation, of dreams and desires. The facts recounted in the diary might have truly happened, but then again, maybe they didn't: they could have simply been imagined by Johan Borg, who, as we know, has been ill and hasn't completely recovered.

And, if the encounters with von Merkens and Heerbrand can be ascribed to the dimension of reality, in part because of the mise-en-scène of these encounters, Veronica Vogler's apparition leaves little doubt as to the nature of the protagonist's mental projections. In this scene, we see Johan sitting down and holding his head between his hands; the sudden appearance of the other, the image-body of desire, takes place at the edge of the shot. Until that moment, the shot had been dominated by a single temporality (which registers Johan Borg on a stony beach). But now it is filled with the other, her subjective time, the time of memory, of remembrance and desire that takes the form of Veronica Vogler, who is also the bearer of a message which highlights the horrific dimension of the film: unbeknownst to Johan, he is being observed by the creatures who populate the island and soon his nightmares will become real. In a single plane, Bergman manages to depict two different temporalities: this is yet another example of how the director's portrayal of time works on different levels. Moreover, as we have seen so far, this multiplicity of levels is reached by stages, and the cohabitation of different times defines an ambiguous difficulty in the relationship between real and imagined [Figs. 12-13].

The same thing happens during the story-confession that Johan tells to Alma after the dinner at the castle: the murder of the young man, who was first crushed against a rocky wall and then beaten to death with stones and thrown into the water. This story, which is depicted in coarse-grained, overexposed images which clearly portray a highly hallucinatory dimension, is yet another loop in the temporal spiral on which the director concentrates. It also corroborates that horizon of doubt, of ambiguousness which is fundamental to the film: the protagonist himself says that he doesn't know if what happened really did happen for real. On the surface, this flashback is similar to the previous three, but in the dramaturgical progression of the film, we are unable to note that it takes place after the turning point represented by the dinner at the von Merkens.

Why is this dinner, this moment which leads to the protagonist's denouement, so important? Because it is at this precise point in Hour of the Wolf that the protagonist's solipsistic dimension gets the upper hand. If, in fact, in the first 
part of the film the dimension of time, of reality, and of that ambiguousness which could veer toward the fantastic was mediated by the figure of Alma, from this point on her mediation vanishes; or better, even when present - like in the sequence in the forest - her mediation is infected by the malady of Johan's demons. This passage takes place during the sequence immediately prior to the dinner sequence, when Johan returns home, sits down at the table, and listens to Alma's boring story of her shopping trip. Johan, in a close-up, turns and looks into the camera long enough for us to understand that it isn't just a look of affection, a look full of empathy and morality; from that moment on, the claustrophobic world of the film will be seen through that look. Johan Borg's mental images will populate the film and will decisively influence the temporal dimension and its continuous slipping between real and imagined.

In the sequence right afterward, when Johan confesses to his wife, Heerbrand shows up at Borg's house and invites the man to another party, where Veronica Vogler will also be present. When he goes away, he leaves a pistol on the table, since both he and Baron von Merkens are not sure that the painter can defend himself against the island's spells. At this point, after a dramatic confrontation between the husband and wife which ends with Johan shooting at Alma and grazing her with the bullet, the film opens up to a dimension of greater unreality. The subtle ambiguousness, which until then had traversed and bathed the happenings and apparitions in a dreamlike and disturbing light, opens up completely to the mental dimension, to the mise-en-scène of the protagonist's ghosts. This eruption of a hallucinatory dimension also defines a complex treatment of time, a fracture characterized by a new quality: time is no longer evoked (for example, by reading a diary or telling a story in the first person); time directly concretizes the interiority of Johan and, at a certain point, symbiotically of Alma, as well.

After the sequence described above, a sharp cut presents us with Johan wandering through the corridors of von Merkens's castle. Here he encounters various characters he had previously met and who now present themselves with their spectral and fantastic attributes: the Baron walks on the walls and the ceiling; Lindhorst takes on the guise of an enormous bird after conducting Borg to the door of Veronica Vogler's room; Veronica appears to be dead but then she reawakens, as all the guests of the castle observe her and Johan, and laugh. It is the moment of the final and definitive confession (in a film which is constructed like a continuous confession), when the masks fall. But the confession is interior, it takes place in the intimacy of the man's mind, which has come unhinged; he now 
only sees what he wants to see. This is made clear by the way time is treated: after the end of this sequence of painful humiliation, there is a cut and we return to Alma as she starts telling her story once again to an invisible listener. The woman says that after Johan shot at her, he left the house but returned a few minutes later and then wrote in his diary for hours. Thus, there is a temporal incongruence between the sequence in the castle and the woman's story. Therefore, what we saw is a form of time which depicts the temporal dimension of the man's interiority. And this temporal dimension is made even more problematic and is pushed to a new extreme: it is this tension which concretely defines the suspended dimension of the fantastical ambiguity of Hour of the Wolf.

Let us observe the sequence of the pre-finale - which takes place in the forest and briefly analyze how it is structured. It opens with Alma running through the forest as she searches for Johan. She finds him sitting on the ground and she hugs him [Fig. 14]. At this point, Bergman, with a fade-out, shows us that Alma is no longer with Johan: in fact, we see that she is with Baron von Merkens. We later see Johan being attacked by the guests of the castle; but then the forest is deserted, Johan has disappeared, and Alma is all alone. This sequence is emblematic of how Bergman uses time to define the horizon of the fantastic: he overthrows the character who is the vector of the interior temporality on which the second part of the film is constructed. If, until this moment, the time we saw portrayed was Johan's, the main protagonist of the sequence in the forest is the man who is attacked and wounded by his demons, but as seen through Alma's eyes.

It is a further example of the mise-en-scène of time: before, Bergman had shown us how the objective dimension of time could coexist on the same plane and in the same shot with its subjective dimension; here, he confronts us with the coexistence of two subjective times: Johan's and Alma's. In fact, he does even more - he adds another loop to that temporal spiral which is the basis of Hour of the Wolf - and does so by letting the woman's temporal dimension be invaded by her husband's. The times intertwine and blend together, making it impossible to distinguish reality from the hallucinated dimension of the fantastic and mental projections.

Bergman's research of time and his ability to make it slip from the objective to the subjective, from the concreteness of the duration to the immeasurable perception of its entirety, creates the indefinite outlines of a mental image which is frayed and ambiguous: an image in which reality can generate the fantastic, with all its demons and ghosts. Thus, Hour of the Wolf portrays the director's attempt to make a plurality of dimensions coexist, in which the borderline 
between reality and the imaginary is cancelled out and leads to that equivalence in which the fantastic possesses the same ontological status as reality.

Starting in the 1960s, Bergman's films traverse new cinematographic territory, reflecting his increasing mastery of the use of the close-up and, at the same time, of the processes for staging a form of purely cinematographic time that is able to bring together the plane of reality with that of the imagination, memory, and dreams. From the union of an explicitly cinematographic technique like the close-up (and the full close-up) and a multifaceted method of representing time, Bergman ferried his own reflections on cinema toward abstraction, consciously and irreversibly. But, at the same time, he rendered increasingly explicit the emotional failure of his characters, who are unable to find authentic human contact, unable to let their faces be convulsed by spasms of emotion: forced, like Andreas Winkelmann in A Passion (Passion, 1969) to wear a neutral mask. A face-surface which reveals nothing and which seems to discourage even the evidence of the inevitable passage of time and life itself.

\section{References}

Aumont, Jacques. 1992. Du visage au cinéma [Face in the Cinema]. Paris: Editions de l'Etoile/Cahiers du Cinéma.

Aumont, Jacques. 2003. Ingmar Bergman. "Mes films sont l'explication de mes images." [Ingmar Bergman. "My Films Are the Explanation of My Images."] Paris: Cahiers du Cinéma.

Béranger, Jean. 1957. Les trois métamorphoses d'Ingmar Bergman [The Three Metamorphoses of Ingmar Bergman]. Cahiers du Cinéma no. 74 (August/ September): 19-28.

Bertetto, Paolo. 2010. La macchina del cinema [The Machine of Cinema]. RomaBari: Laterza.

Donner, Jörn. 1970. Ingmar Bergman. Paris: Editions Seghers.

Douchet, Jean. 1959. L’instant privilégié [The Pregnant Moment]. Cahiers du Cinéma no. 95 (May): 51-53.

Estève, Michel. 1966. Nattvardgästerna (Les Communiants) ou le silence de Dieu [Nattvardgästerna (The Communicants) or the Silence of God]. Études cinématographiques no. 46-47 ( $1^{\text {st }}$ trimester).

Gervais, Marc. 1999. Ingmar Bergman. Magician and Prophet. Montreal \& Kingston/London/Ithaca: McGill-Quenn's University Press.

Godard, Jean-Luc. 1958. Bergmanorama. Cahiers du Cinéma no. 85 (July): 1-5. 
Hoveyda, Fereydoun. 1959. Le plus grand anneau de la spirale [The Largest Ring of the Spiral]. Cahiers du Cinéma no. 95 (May): 40-47.

Narboni, Jean. 1967. Ingmar Bergman: Le festin de l'araignée [The Feast of Blood]. Cahiers du Cinéma no. 193 (September): 34-41.

Neyrat, Cyril. 2007. Le dompteur de démons [The Tamer of Demons]. Cahiers du Cinéma. Hors-série: 11-13.

Rohmer, Eric. 1956. Présentation d'Ingmar Bergman [Presentation of Ingmar Bergman]. Cahiers du Cinéma no. 61 (July): 7-9.

Steene, Birgitta. 2005. Ingmar Bergman. A Reference Guide. Amsterdam: Amsterdam University Press.

Vineberg, Steve. 2000. Persona and the Seduction of Performance. In Ingmar Bergman's Persona, ed. Lloyd Michaels, 110-129. Cambridge/New York/ Melbourne: Cambridge University Press.

\section{List of Figures}

Figures 1-4. Close-ups in Persona (1966), Waiting Women (1952), Cries and Whispers (1972), Winter Light (1963).
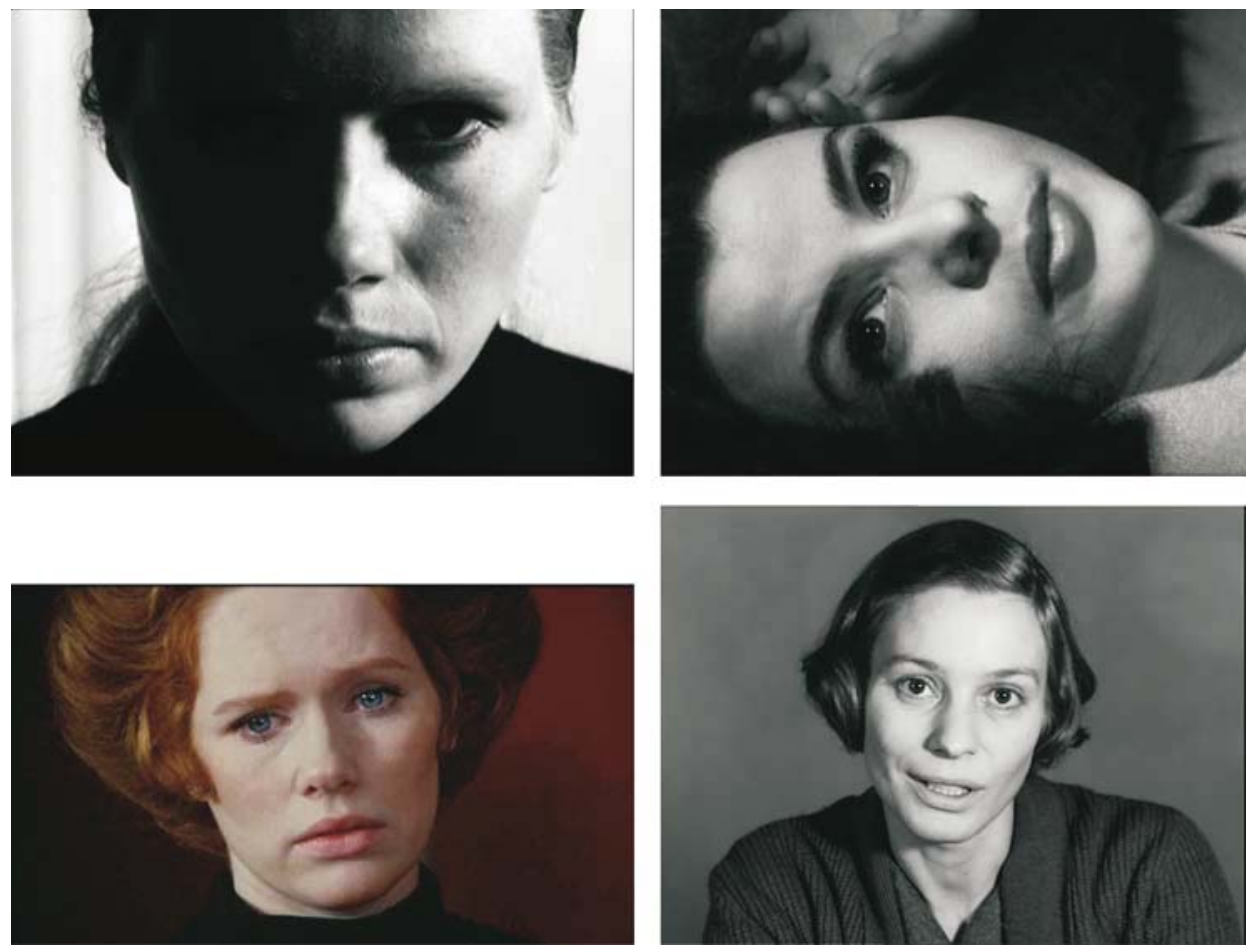
Figure 5. Winter Light (1963): a close-up evoked by its very absence.

Figure 6. The pain, in its visual effects on the body, marks the inexorable passage of time which consumes and destroys.
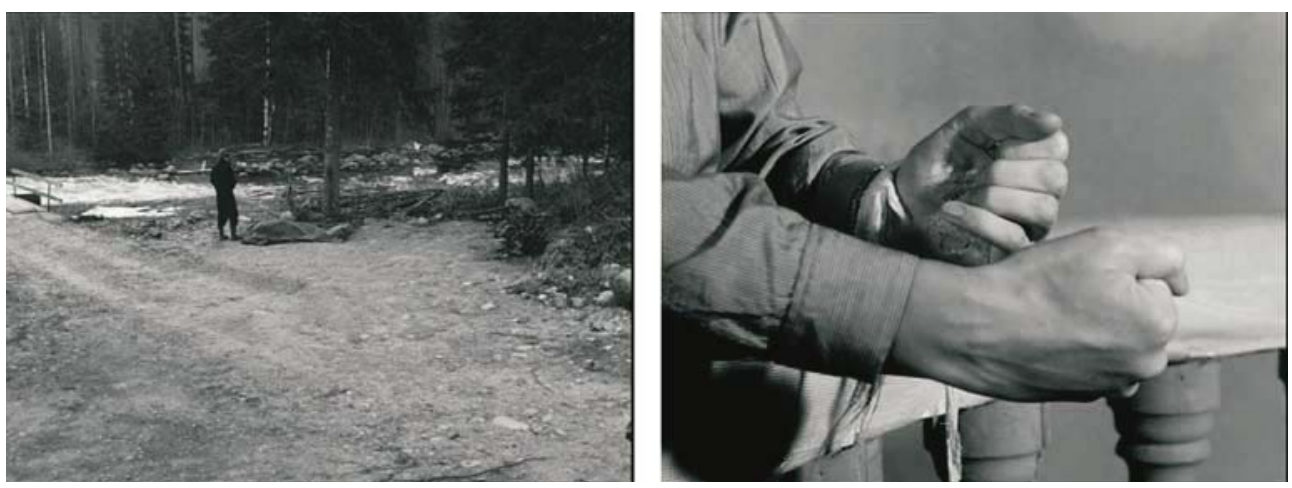

Figure 7. Persona (1966): a world suspended between the concreteness of reality and the impalpability of dreams.

Figure 8. The close-up as the location of the confusion between the objective dimension afferent to the world and the character's own subjectivity.
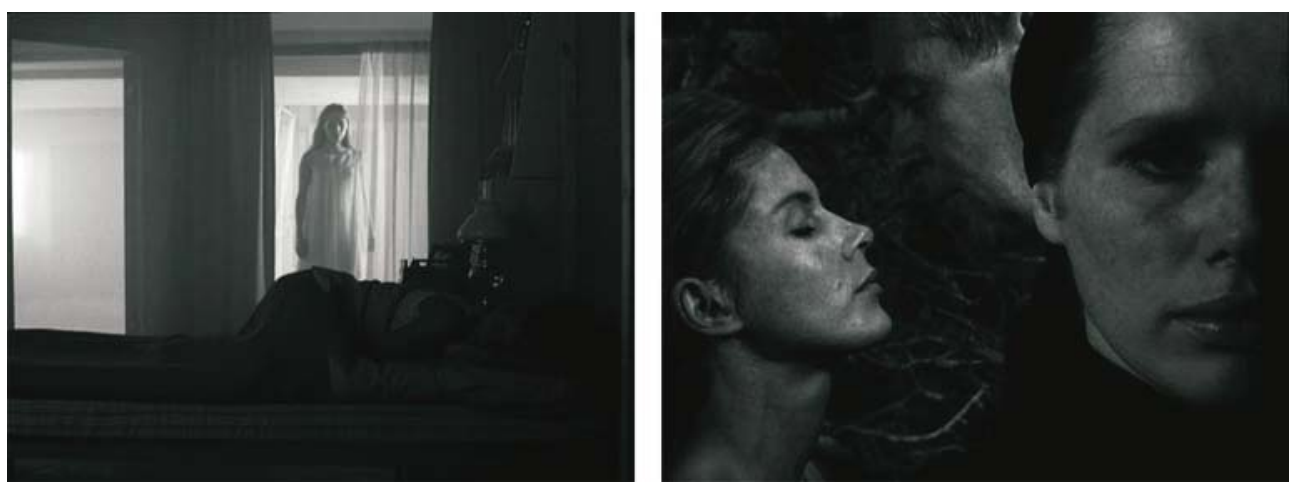
Figures 9-14. Hour of the Wolf (1968).
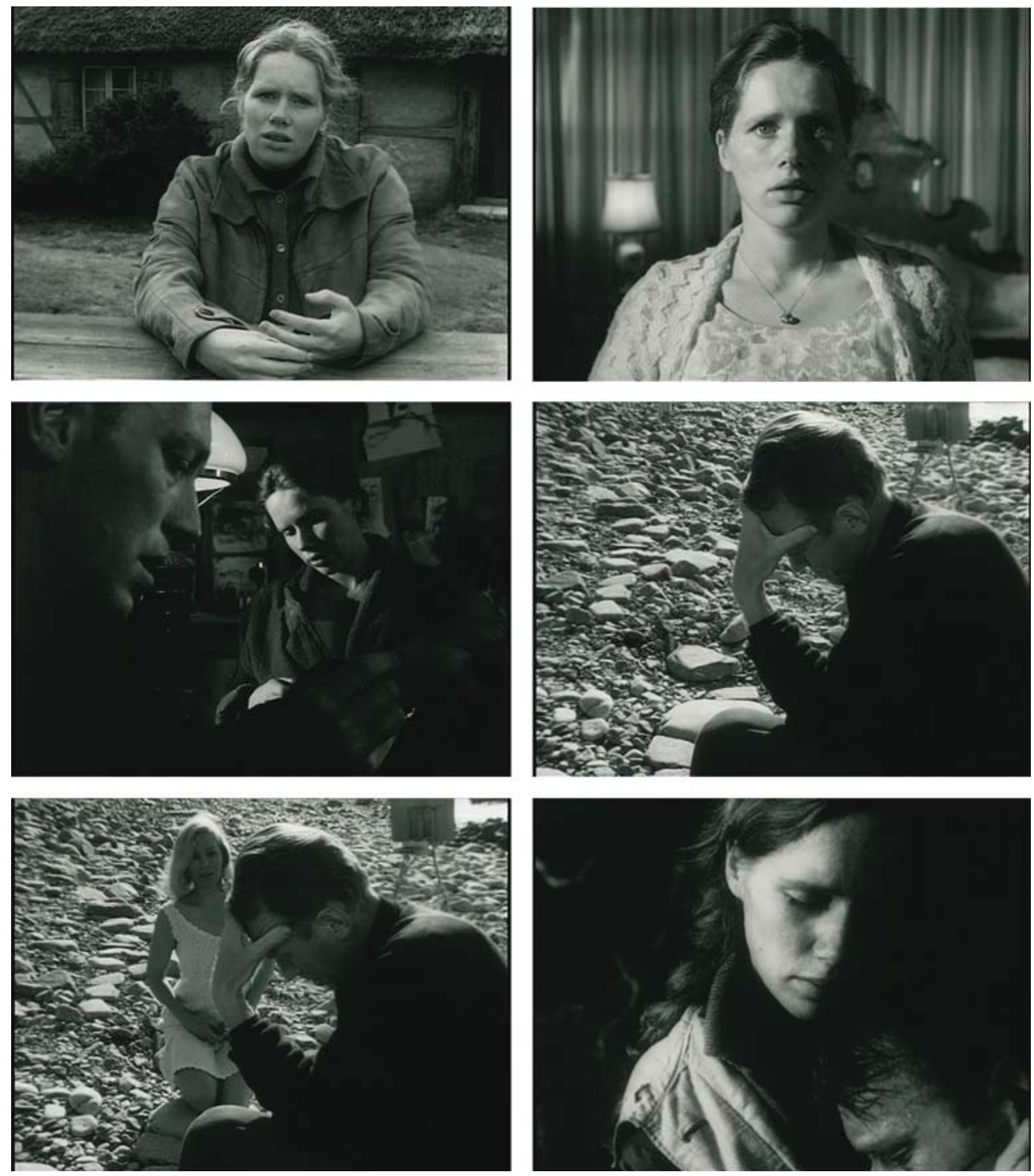